\title{
Genetic diversity and different cross- neutralization capability of porcine circovirus type 2 isolates recently circulating in South Korea
}

Seok-Jin Kang ${ }^{1+}$, Hyeonjeong Kang ${ }^{1+}$, Su-Hwa You' ${ }^{1}$, Hye Jeong Lee ${ }^{1}$, Nakhyung Lee ${ }^{2}$, Bang-Hun Hyun ${ }^{1}$ and Sang-Ho $\mathrm{Cha}^{1 *}$ (D)

\begin{abstract}
Background: Porcine circovirus type 2 (PCV2) is a small single-stranded DNA virus and a primary cause of PCVassociated diseases (PCVAD) that result insubstantial economic loss for swine farms. Between 2016 and 2018, PCV2 field viruses were isolated from PCVAD-affected swine farms in South Korea and investigated for genetic and antigenic heterogeneity.

Results: The genetic analysis of ORF2 showed that the genotype of the Korean PCV2 field isolates has been rapidly shifted from PCV2a or 2b to mutant PCV2b known as PCV2d with 82.6 to $100 \%$ amino acid sequence similarity. PCV2-specific monoclonal antibodies (mAbs) demonstrated variable antigen-binding activity to four representative Korean PCV2 field isolates [QIA215 (PCV2a), QIA418 (PCV2b), QIA169 (PCV2d), and QIA244 (PCV2d)] without genotype specificity, and one mAb showed neutralization activity to QIA215. In a cross-virus neutralization assay using anti-PCV2 sera of pigs and guinea pigs injected with a commercial vaccine and the Korean PCV2 field isolates, the anti-porcine sera of a commercial vaccine had high neutralization activity against QIA215 and QIA418 with statistically lower activity against PCV2d viruses. Anti-guinea pig sera of QIA215, QIA418, QIA169, and a commercial vaccine had high neutralization activity against all of the viruses with significantly lower activity against QIA244. Importantly, anti-guinea pig sera of QIA244 had high neutralization activity against all of the viruses.

Conclusions: This study confirmed genetic and antigenic diversity among recent PCV2 field isolates in Korean swine farms, and the strain-based difference in virus neutralization capability should be considered for more effective control by vaccination.
\end{abstract}

Keywords: Porcine circovirus type 2, Genotype, Antigenic diversity, Neutralization

\footnotetext{
* Correspondence: virusmania@korea.kr

${ }^{\dagger}$ Seok-Jin Kang and Hyeonjeong Kang contributed equally to this work.

${ }^{1}$ Viral Disease Division, Animal and Plant Quarantine Agency, 177, Hyeoksin

8-ro, Gimcheon-si, Gyeongsangbuk-do 39660, Republic of Korea

Full list of author information is available at the end of the article
}

(C) The Author(s). 2020 Open Access This article is licensed under a Creative Commons Attribution 4.0 International License, which permits use, sharing, adaptation, distribution and reproduction in any medium or format, as long as you give appropriate credit to the original author(s) and the source, provide a link to the Creative Commons licence, and indicate if changes were made. The images or other third party material in this article are included in the article's Creative Commons licence, unless indicated otherwise in a credit line to the material. If material is not included in the article's Creative Commons licence and your intended use is not permitted by statutory regulation or exceeds the permitted use, you will need to obtain permission directly from the copyright holder. To view a copy of this licence, visit http://creativecommons.org/licenses/by/4.0/ The Creative Commons Public Domain Dedication waiver (http://creativecommons.org/publicdomain/zero/1.0/) applies to the data made available in this article, unless otherwise stated in a credit line to the data. 


\section{Background}

Porcine circovirus type 2 (PCV2) causes severe economic loss in the swine industry worldwide. PCV2 infection is associated with various diseases, including porcine circovirus-associated disease (PCVAD), postweaning multi-systemic wasting syndrome (PMWS), porcine dermatitis and nephropathy syndrome (PDNS), and reproductive failure in pigs, especially when infected with porcine reproductive respiratory syndrome (PRRS) virus, porcine parvovirus (PPV), and mycoplasma, which lead to decreased production efficiency.

PCV2 is a small, non-enveloped virus with a circular, single-stranded DNA genome, and it is comprised of two major proteins, ORF1 and ORF2. The ORF1 on the positive strand encodes two nonstructural proteins (RepRep'), which are essential for viral replication. The OFR2, namely capsid protein on the complementary strand, binds to the host receptor and induces immune responses [1]. Based on ORF2 nucleotide sequences, the genotypes of PCV2 have been commonly classified as PCV2a, 2b, 2c, 2d, and 2e [2-5].

PCV2a was the dominant genotype in pig herds until the early 2000s. After introduction of the PCV2a-derived vaccine in 2006, PCV2b became the dominant genotype inthe late 2000s [6-8]. Since the PCV2d genotype was first reported in China and the US in the early of 2010s, the rapid spread of PCV2d has been documented worldwide $[4,9]$. In 2013, the PCV2d genotype was first isolated from cases of vaccine failure in Korea [10] and appeared highly prevalent afterward [11]. Besides, the PCV2d genotype was reported to have virulence comparable to PCV2a and 2b [12].

Commercial vaccines based on PCV2a have been applied to the field since 2006 and are recognized as an effective tool to control outbreaks of PCVAD. However, many outbreaks of PCVAD have been recently reported from the farms vaccinated with PCV2a-based vaccines, from which field viruses of the PCV2d genotype have been isolated along with disappearance of PCV2a genotype strains. The genotype shift in the field has suggested that PCV field isolates may have gone through antigenic mutations, leading to escape from immune responses induced by commercially available vaccine strains [13-15]. Due to rapid change of PCV2 genotype and continuous reports of vaccine failure in the field, it is necessary to investigate the prevalence of PCV2 infection and genetic variation. Therefore, we isolated PCV2 field viruses from swine farms vaccinated mostly with commercial PCV2a-based vaccines from 2016 to 2018, and investigated genetic diversity and difference of cross-neutralization activity of the field viruses.

\section{Results}

Genetic analysis of PCV2 circulating in swine farms of Korea

In ORF2 PCR of the clinical samples, PCV2-positive ratio of tissues $(50.3 \%)$ were higher than that of sera (24.4\%) in 2016. In the following detection, the PCV2 -positive ratio of tissues were 69.5 and $52.4 \%$ for 2017 and 2018 , respectively. Totally, $57.5 \%(288 / 501)$ of the tissues were positive (Table 1). Regarding the phylogenetic analysis based on ORF2 sequence $(n=164)$, all of the Korean isolates were classified into PCV2a $(n=4)$, $2 \mathrm{~b}(n=29)$, and $2 \mathrm{~d}(n=131)$, with $2.4,17.7$, and $79.9 \%$ infection rates, respectively (Fig. 1a and b). The isolation rate of PCV2a, 2b, and 2d field viruses from 2016 to 2017 was 2.7 to $5.7 \%, 27.8$ to $28.3 \%$, and 69.4 to $66.0 \%$, respectively. In 2018, PCV2a was not detected, and PCV2b was isolated as 5.3\% in the field, whereas PCV2d genotypes accounted for $94.7 \%$ of field isolates. In the pair-wise comparison of ORF2 NT and AA sequences, the NT (AA) sequence similarity of PCV2a, PCV2b, and PCV2d was 97.3 to $99.4 \%$ (96.2-99.6\%), 97.5 to $100 \%$ (97.0-100\%), and 97.6 to $100 \%(92.4-100 \%)$, respectively, whereas the NT (AA) sequence similarity of all genotypes was 88.2 to $100 \%$ (82.6-100\%) (Fig. 1c).

\section{Diverse reactivity of PCV2-specific mAbs against PCV2 genotypes}

Based on the ORF2 AA sequence, the representative strains (QIA215, QIA418, QIA169, and QIA244) were examined for antigen-binding activity to mAbs. The six PCV2-specific mAbs showed diverse reactivity to PCV2 field viruses. As shown in Fig. 2, mAb-1 and mAb-3 had similar reactivity to PCV2 field viruses. In the case of mAb-2, it had significantly lower reactivity to QIA169 than the others. mAb-4 had significantly lower reactivity to QIA418 than other viruses. mAb-5 had significantly higher reactivity to QIA215 and QIA418 than other viruses. mAb-6 showed significantly lower reactivity to QIA244 than other viruses. The mAbs (1/200-1/3200 dilution) were mixed with the representative strains to evaluate neutralization activity. In results (Fig. 3), most of the mAbs did not have neutralization activity against all of field viruses, whereas only $\mathrm{mAb}-2$ showed

Table 1 Information of clinical samples

\begin{tabular}{lll}
\hline & No. of farms & Sera \\
\cline { 2 - 3 } & Tissues & $361(24.4)$ \\
\hline 2016 & $157(50.3)$ & - \\
2017 & $178(69.5)$ & - \\
2018 & $166(52.4)$ & $361(24.4)$ \\
Total & $501(57.5)$ &
\end{tabular}

Parentheses is the PCV2-positive ratio (\%). Multiple clinical samples collected from single farm were counted as one 

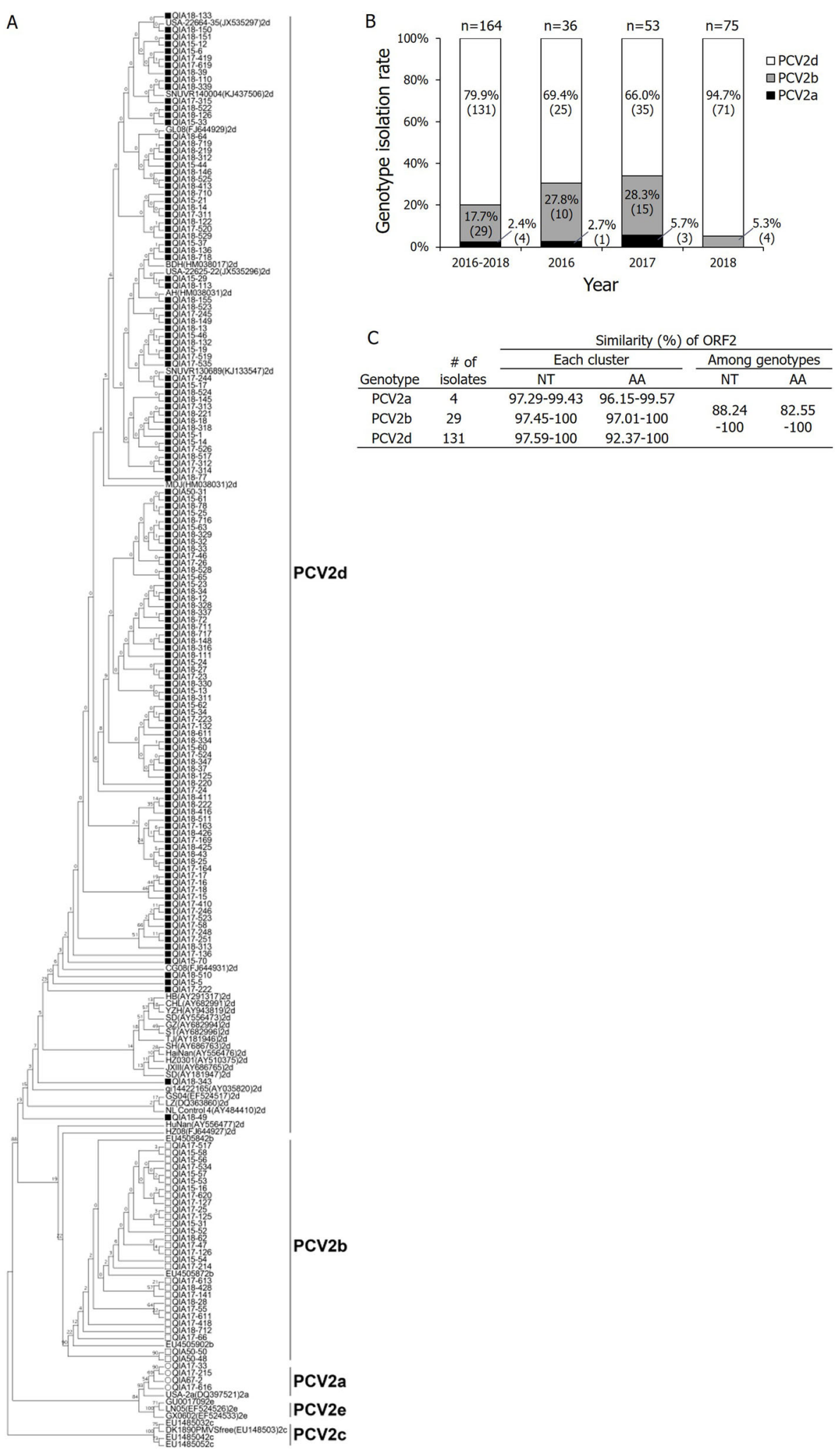

V2d 

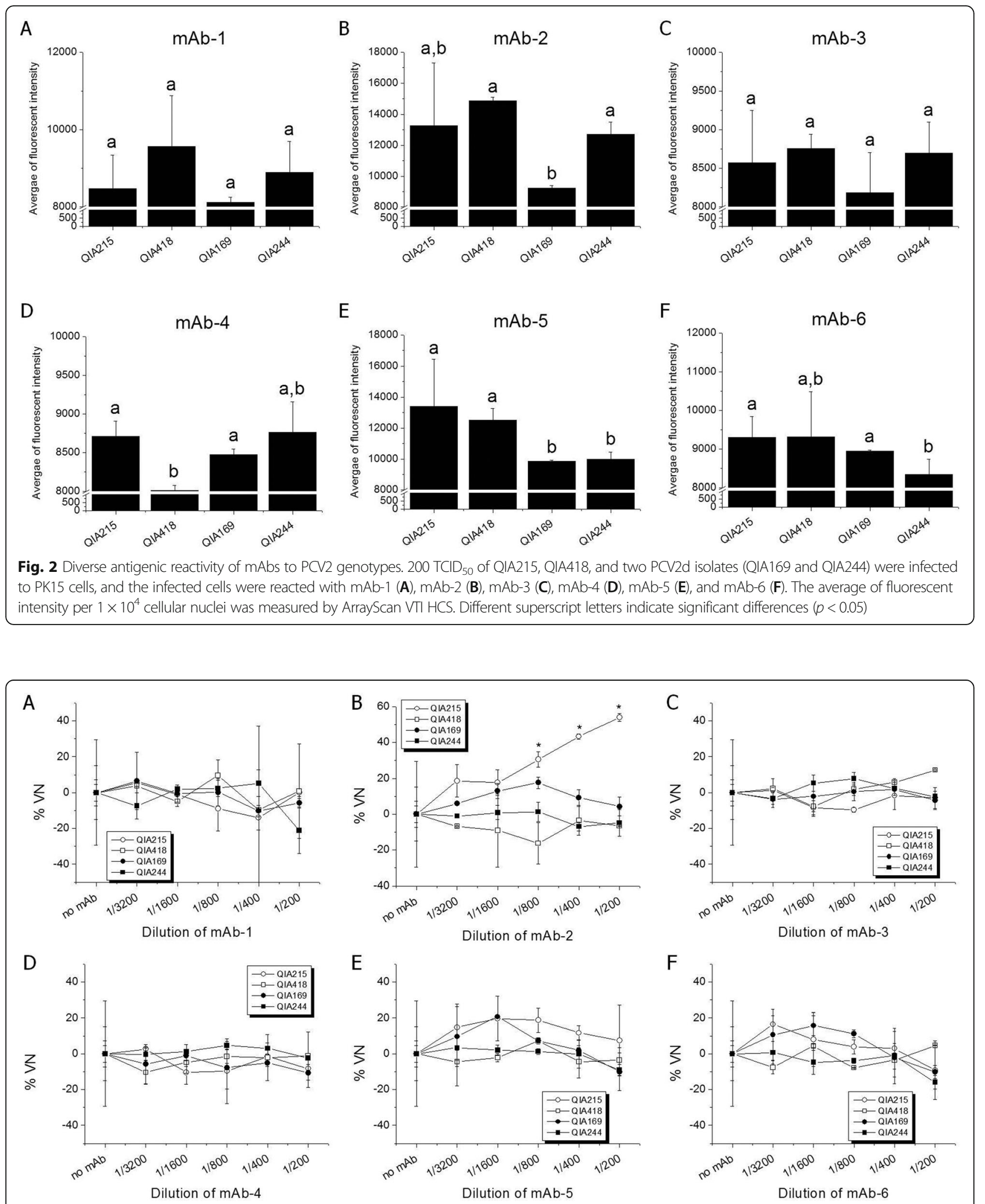

Fig. 3 Neutralization assay using mAbs for PCV2 genotypes. 200 TCID 50 of QIA215 (0), QIA418 (), QIA169 (•), and QIA244 (匹) were neutralized withdiluents (1/200 to 1/3200) of mAb-1 (a), mAb-2 (b), mAb-3 (c), mAb-4 (d), mAb-5 (e), and mAb-6 (f), and the neutralized mixtures were infected on PK15 cells. The fluorescent intensity of PCV2-positve cells at day 5 of post-infection was determined as a \%VN by immunostaining with mAb-2 having the reactivity against all PCV2 genotypes. *Significantly different from control at $p<0.05$ 


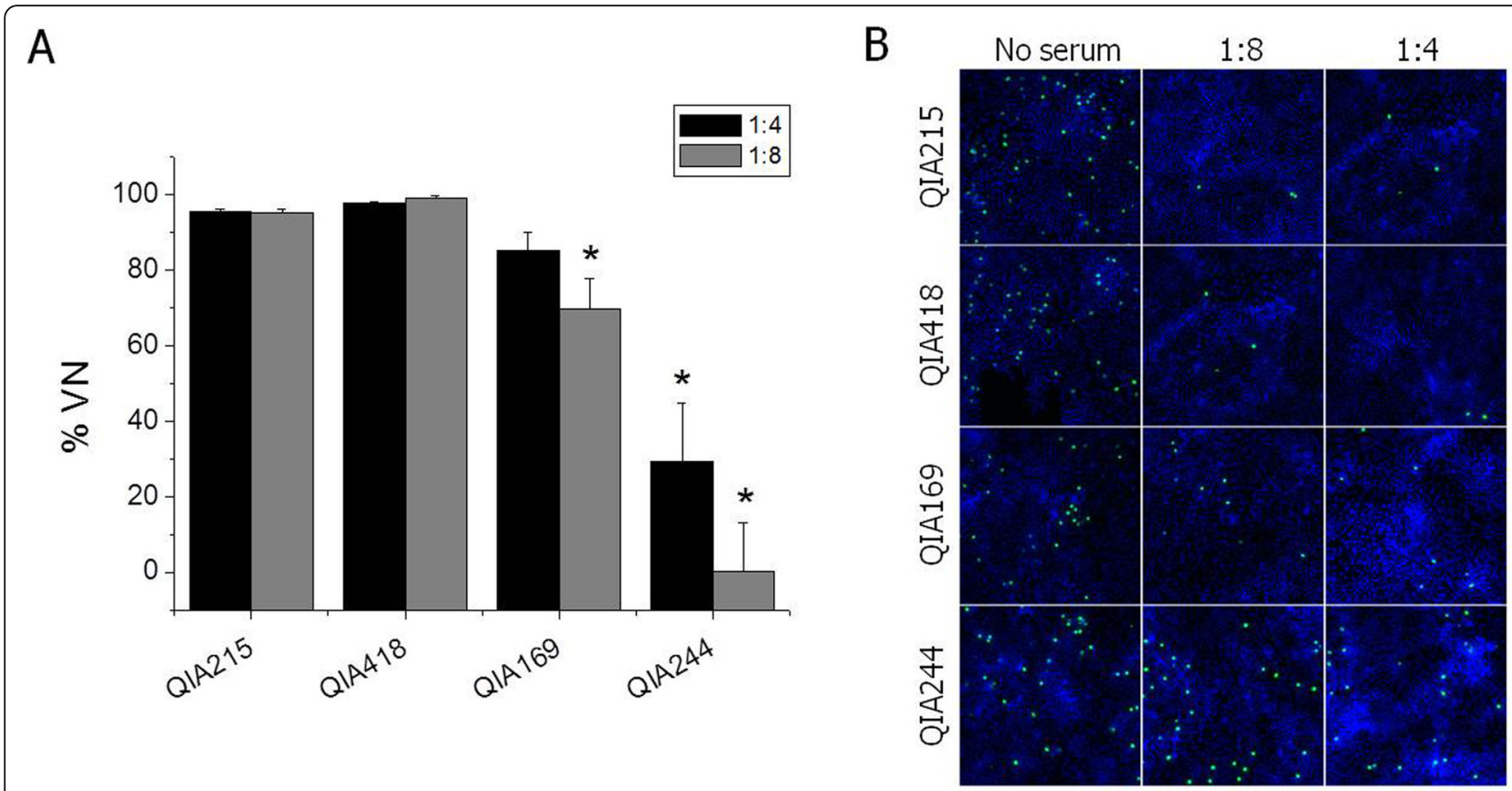

Fig. 4 Viral neutralization assay using anti-PCV2 pig sera. a Anti-sera collected from SPF pigs vaccinated with Ingelvac CircoFLEX were neutralized with homologous and heterologous genotypes of PCV2. *Significantly different from control at $p<0.05$. b The \%VN of Fig. 4a was converted from the number of PCV2-positive cells counted per $1 \times 10^{4}$ cells using ArrayScan VTI HCS. Nuclei were counterstained with Heches33258. The merged images were magnified as $100 \times$

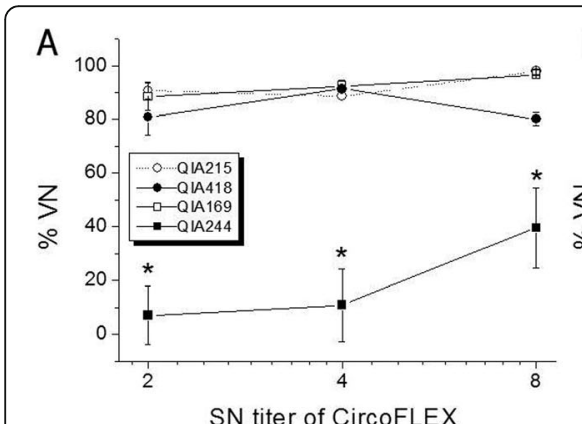

SN titer of CircoFLEX

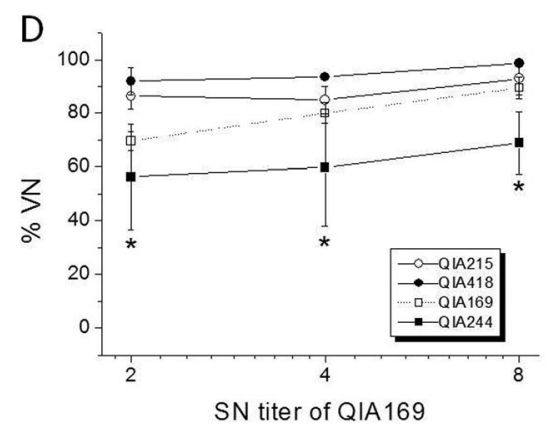

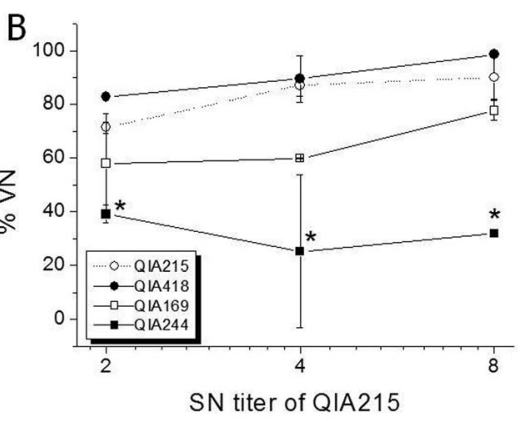
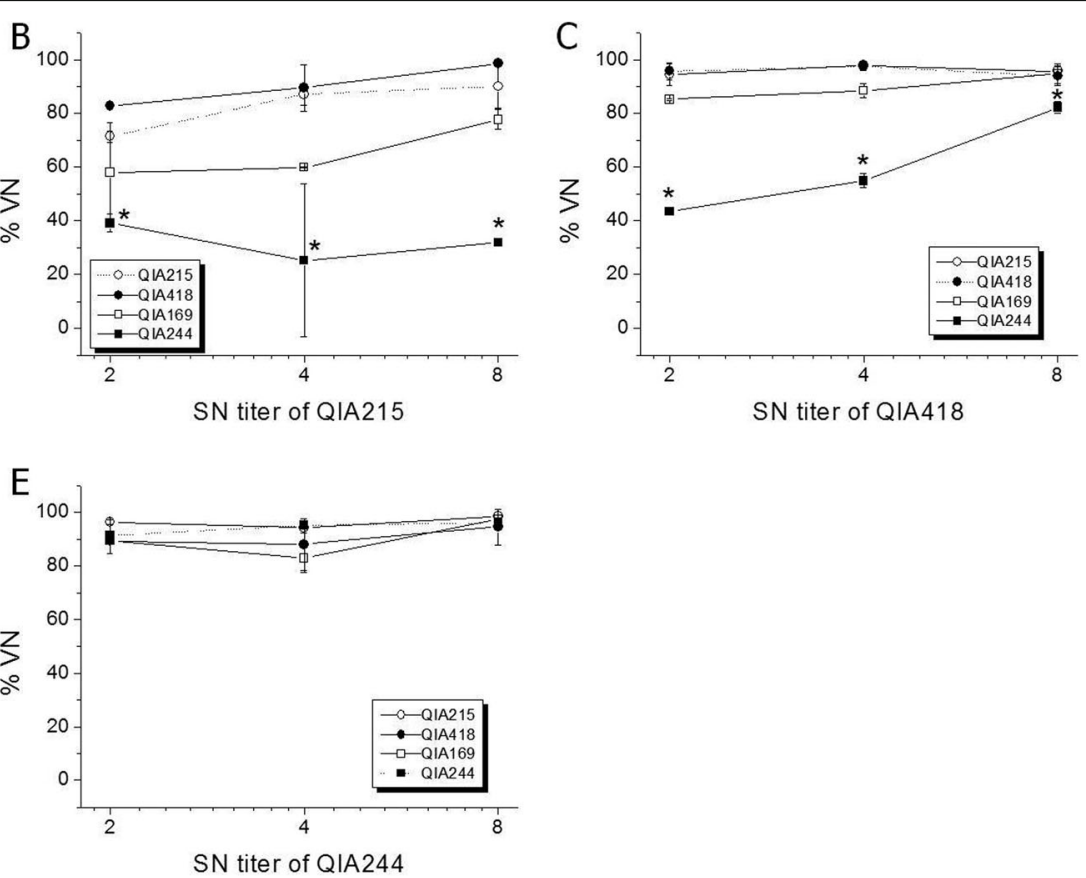

Fig. 5 Evaluation of cross-protection capability (\%VN) among different PCV2 genotypes. The anti-sera collected from guinea pigs vaccinated with Ingelvac CircoFLEX (a), QIA215 (b), QIA418 (c), QIA169 (d), and QIA244 (e) were neutralized with four PCV2 viruses: QIA215 (o), QIA418 (口), QIA169 $(\bullet)$, and QIA244 (घ). Cross-protection efficiency among genotypes was evaluated using anti-sera of 1:2 to 1:8 SN titer against homologous viruses (dot line). *Significantly different from control at $p<0.05$ 
neutralization activity (\%VN of $30.5-53.9 \%$ ) only against QIA215 at $1 / 200$ to $1 / 800$ dilution.

\section{Cross-virus neutralization of anti-PCV2 sera}

To evaluate cross-neutralization activity among PCV2 strains, anti-PCV2 sera produced from pigs and guinea pigs were reacted with homologous and/or heterologous (genotype) viruses. For anti-pig sera injected with a commercial vaccine containing PCV2a capsid protein, the $\% \mathrm{VN}$ was larger than 95\% against QIA215 and QIA418 at 1:4 and 1:8 SN titer, and was significantly lower against PCV2d strains $(69.9 \%$ for QIA169 at 1:8 SN titer, 29.3 and $0.3 \%$ for QIA244 at 1:4 and 1:8 SN titer, respectively) than against QIA215 or QIA418 (Fig. 4). When anti-guinea pig sera were applied to the virus neutralization assay, the \%VN of anti-commercial vaccine sera was 80 to $95 \%$ against QIA215, QIA418, and QIA169 at all SN titers (Fig. 5a). The \%VN of antiQIA215 sera was approximately 80 to $100 \%$ against the homologous viruses, QIA418 and QIA169, without statistical difference at all SN titers (Fig. $5 \mathrm{~b}$ ). The \%VN of anti-QIA418 sera was more than $85 \%$ against the homologous viruses, QIA215 and QIA169, at all SN titers (Fig. 5c). The \%VN of anti-QIA169 sera was 80 to $100 \%$ against the homologous viruses, QIA418 and QIA215, without statistical difference (Fig. 5d). It was noted that the $\% \mathrm{VN}$ of all of anti-sera except anti-QIA244 sera was statistically lower against QIA244 than the homologous or other heterologous viruses. The \%VN against the QIA244 strain was 7.0 to $39.6 \%, 25.2$ to $39.1 \%, 43.5$ to $82.3 \%$, and 56.4 to $68.8 \%$ for anti-sera of CircoFLEX, QIA215, QIA418, and QIA169 at all SN titers, respectively. Moreover, the \%VN of anti-QIA244 sera was 80 to $98 \%$ against all of the homologous and heterologous viruses at all SN titers without statistical difference (Fig. 5e). In the further evaluation of viral neutralization activity against QIA244 using anti-PCV2 guinea pig sera between <1:2 and 1:32 SN titer, the \%VN against QIA244 were 0 to $88.0 \%, 0$ to $76.6 \%, 0$ to $87.0 \%$, and 0 to $89.0 \%$ at all SN titers for anti-sera of CircoFLEX, QIA215, QIA418, and QIA169, respectively, which were significantly lower than those against each homologous virus (Fig. 6).

\section{Discussion}

PCV2a was the only genotype isolated in the field before the PCV2a-based vaccination. However, since the PCV2a vaccine was applied to the field in 2006, the genotype shift to PCV2b and PCV2d emerged and was expedited over time, and PCV2d became the dominant genotype around the world. In the present study, 164 PCV2 field viruses were isolated from clinical samples from 2016 to
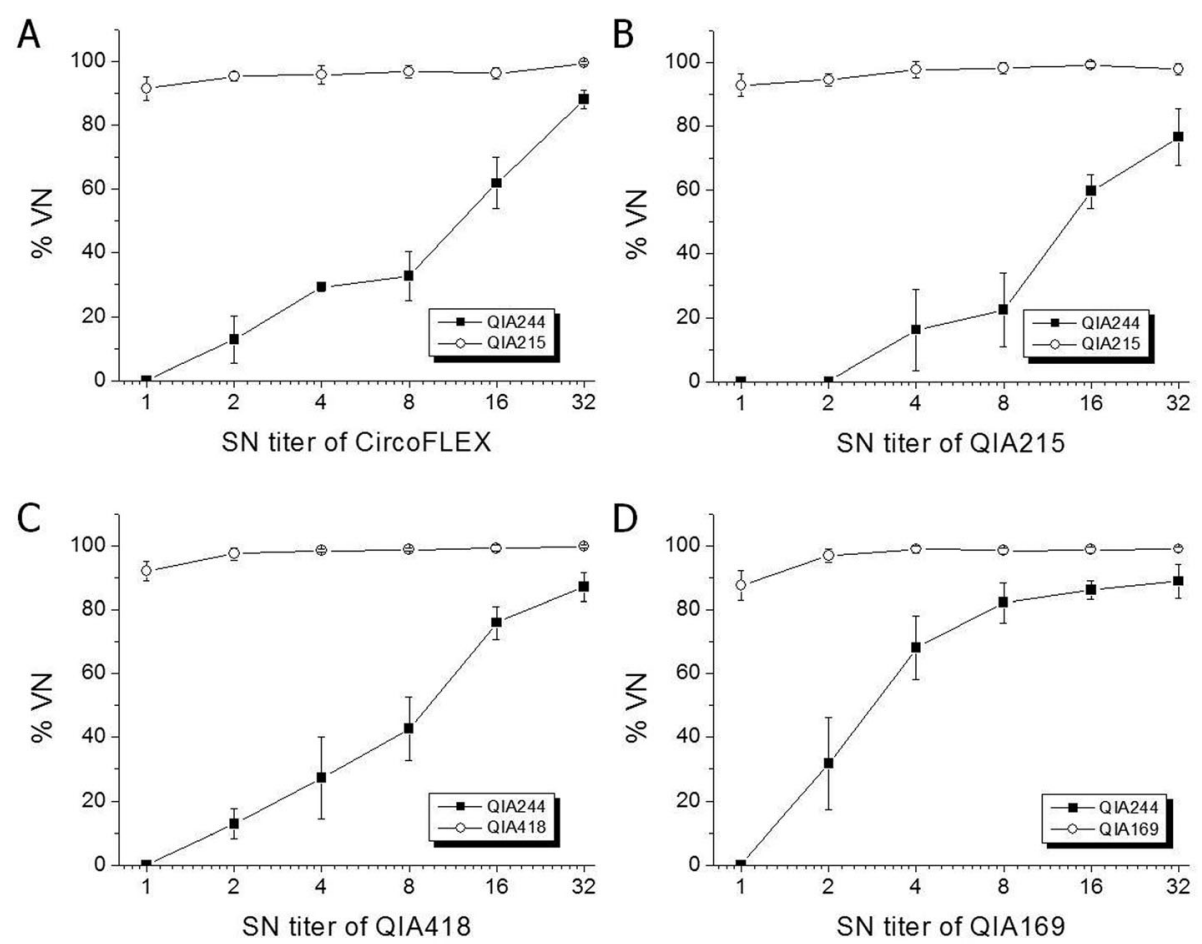

Fig. 6 Further evaluation of viral neutralization activity (\%VN) against QIA244 using anti-PCV2 guinea pig sera derived from different genotypes of PCV2. QIA244 isolates were neutralized with anti-sera of Ingelvac CircoFLEX (a), QIA215 (b), QIA418 (c), and QIA169 (d) of up to 1:32 SN titer. As a control, homologous viruses were compared for each anti-serum. *Significantly different from control at $p<0.05$ 
2018 in Korea to investigate genetic diversity and antigenic relatedness based on PCV2-specific mAb reaction and cross-neutralization activity of anti-PCV2 sera. ORF2 (capsid protein) sequence analysis showed that PCV2d has become a predominant genotype circulating in Korean swine farms with approximately $80 \%$ of isolation rates, whereas other genotypes were hardly isolated, with less than 3 and $18 \%$ for PCV2a and PCV2b, respectively. Further, the Korean field isolates of PCV2d showed up to $82.6 \%$ with PCV2a isolates, and also ranged from 92.4 to $100 \%$ among the same genotype for amino acid sequence similarity of the capsid protein. The prevalence of PCV2 genotypes was similar to the recent study [16]. Even though PCV2a was hardly found, there has been continuous isolation of PCV2b with even a small proportion in Korean swine farms. However, it was anticipated that the genotype may completely disappear in near future, because PCV2a-based commercialized vaccine neutralized PCV2b isolate better than PCV2d isolate as shown in this study (Fig. 4), and was highly protective against PCV2b isolates in pigs [17]. The possible effect of the PCV2a vaccination on the genotype shift was documented in previous reports [13$15]$, suggesting that the vaccination has the great potential to be a cause of vaccine-escaping mutants in the field. Therefore, along with the drastic genotype shift, the wide range of amino acid sequence differencesin capsid protein for Korean recent field isolates suggested that the substantial antigenic variability including neutralization activity of the viruses also should be investigated. Despite extensive documentation of the genetic variation of PCV2, the antigenic diversity of PCV2 has not been well studied. The antigenic diversity among PCV2 strains was first demonstrated by the use of monoclonal antibodies [18], whereas there was no difference of antigenic reactivity in Korean field PCV2d isolated from a vaccine failure farm [10]. We also investigated the antigenic diversity among PCV2 field viruses by the antigenic reaction and virus neutralizing activity of mAbs and anti-PCV2 sera. As shown in Fig. 2, mAb-5 showed strong reaction with PCV2a, and $2 \mathrm{~b}$, but not PCV2d genotype. Two mAb (mAb-1 and mAb-3) were bound to all of the genotypes in similar specificity. The others (mAb-2, mAb-4, and mAb-6) were reacted with PCV2 viruses, regardless of genotype. Also, it was noted that $\mathrm{mAb}-2$ had neutralizing activity only against QIA215, as shown in Fig. 3. The previous study also reported that $\mathrm{mAb} 8 \mathrm{E} 4$, an antibody produced against a PCV2a isolate, neutralized only PCV2a [19]. Even if there has been no information about neutralization activity between the mAbs and PCV2d strains, the diverse reactivity of the mAbs against field isolates in this study suggested that the antigenic variability of neutralizing or non-neutralizing epitopes may exist among PCV2 genotypes as well as within the same genotype, failing to find genotype-specific $\mathrm{mAb}$, as in the previous studies.

The neutralization activity of anti-PCV2 sera varied among the field viruses. Importantly, anti-PCV2 swine sera of the current commercial vaccine had low virus neutralization activity by less than $30 \% \mathrm{VN}$ against a PCV2d strain, QIA244. At the same time, in crossneutralization using anti-PCV2 guinea pig sera, each of the anti-PCV2 sera effectively neutralized the same genotype virus or the different genotype viruses except one of the PCV2d strains, QIA244. As shown in the results, while a PCV2d virus, QIA169, was efficiently neutralized by anti-sera of all viruses, the other PCV2d virus, QIA244, was not fully neutralized by anti-guinea pig sera of up to 1:32 SN titer. The low neutralization activity against the PCV2d virus, QIA244, was expected from the lowest ORF2 amino acid sequence similarity of QIA244 with other viruses (91.6\% between QIA215 and QIA418; 89.7\% between QIA215 and QIA169; 89.4\% between QIA215 and QIA244; 93.1\% between QIA418 and QIA169; 92.8\% between QIA418 and QIA244; and 99.3\% between QIA169 and QIA244). Importantly, the low neutralization activity within the PCV2d viruses (QIA244 vs. QIA169) was unexpected. In terms of crossprotection among different genotype viruses, experimental studies for cross-protection between genotypes showed that PCV2a- or PCV2b-based commercial vaccine was protective against concurrent infection of different genotype viruses (PCV2b and PCV2d strains) in pigs [20]. Nevertheless, experimental evidence from the controlled studies also supported that a viremia was effectively decreased by homologous vaccine more than heterologous vaccine in a concurrent PCV2a and PCV2d challenge [21]. Besides, viremia and shedding of virus were still observed in PCV2a-vaccinated pigs, although the viral load was decreased after the PCV2d challenge [22], which was observed from the studies using challenging viruses of other genotypes [12, 22-24]. Moreover, mutant PCV2b (PCV2d) was isolated from vaccinated farms $[4,10]$. Therefore, the different virus neutralization efficiency among the same genotypes in this study and inconsistent protective efficacy of vaccine against the same genotype challenges in the previous studies suggest that the neutralization activity of PCV2 may be highly diverse among field strains in the field. Besides, since we observed differences of amino acid residues of the capsid protein between QIA169 and QIA244, further studies to clarify which amino acid is responsible for the difference of neutralization activity are needed to be conducted by mutating the amino acid residue of QIA244 to that of QIA169.

\section{Conclusions}

This study confirmed genetic variation including a dramatic genotype shift (from PCV2a or PCV2b to PCV2d) 
and demonstrated different virus neutralization activity of field isolates recently circulating in Korean swine farms, suggesting that the strain-based difference in virus neutralization capability should be considered for more effective control by vaccination.

\section{Methods}

\section{Clinical samples and isolation of viruses}

Clinical samples including 361 sera and 501 tissues (lungs and lymph nodes) were obtained from the nationwide farms $(n=862)$ where the disease diagnosis was requested due to the problem of respiratory and wasting syndromes from 2016 to 2018. Tissues and sera were collected in 2016, and only tissues were collected from 2017 to 2018 due to the higher viral detection efficiency in tissues. We described the detailed sample collection in Table 1. All PCV2-positive clinical tissue sampleswere used for viral isolation and genetic analysis.

The tissue samples $(300-500 \mathrm{mg})$ were homogenized in phosphate-buffered saline (PBS) with MagNALyser Green Beads (Roche Diagnostics, Mannheim, Germany) and Precellys 24 homogenizer (Bertin Technologies, Montigny-le-Bretonneux, France) according to the manufacturer's instructions. Homogenized tissues were centrifuged at $13,000 \mathrm{rpm}$, at $4{ }^{\circ} \mathrm{C}$ for $5 \mathrm{~min}$, and the supernatants were transferred into sterile Eppendorf tubes. The tissue homogenates and sera were kept at $-70^{\circ} \mathrm{C}$ until use. To detect PCV2 in the clinical samples, the ORF2 gene (493 bp) was amplified using the HotStarTaq Plus Master Mix Kit and ORF2-specific forward primers (5'-CACGGATA TTGTAGTCCTGGTCG-3') and reverse primers (5'CGCACCTTCGGATATACTG-3').

PCV2-positive clinical tissue extracts were infected with PK15 cells, which were all types of PCV-free as confirmed by PCR, and PCV2 isolates including PCV2a, 2b, and 2d genotypes were propagated with high titer $\left(10^{5}-10^{6}\right.$ $\mathrm{TCID}_{50} / \mathrm{mL}$ ). Viral titration was conducted following the previous report [25] and viral titers were determined by immunostaining using PCV2-specific monoclonal antibodies (mAbs). Based on the amino acid sequence of ORF2 and growth efficiency in PK15 cells, representative isolates of two PCV2d (QIA169 and QIA244) were selected for evaluation of cross-reactivity along with PCV2a (QIA215) and PCV2b (QIA418) genotypes.

Preparation of monoclonal antibodies ( $\mathrm{mAbs}$ ) and anti-sera Six PCV2-specific mAbs named mAb-1, mAb-2, mAb-3, $\mathrm{mAb}-4, \mathrm{mAb}-5$, and $\mathrm{mAb}-6$ were kindly provided by Median Diagnostics Inc. and BioPOA Ltd., Korea. These mAbs were produced by immunizing mouse (Balb/c, $n=3$ ) with PCV2a viruses and selected based on the specific reactivity tocapsid proteins of the PCV2a viruses. Anti-PCV2 sera of specific pathogen-free (SPF) pigs vaccinated with Ingelvac CircoFLEX (Boehringer Ingelheim Vetmedica, Rohrdorf,
Germany) were also kindly provided by Median Diagnostics Inc. The anti-PCV2 pig sera were pooled to be used for viral neutralization assay. Anti-PCV2 sera of guinea pigs were prepared by injection of QIA215, QIA418, QIA169, QIA244, and Ingelvac CircoFLEX into guinea pigs (three heads for each virus). For the first injection, the field viruses $\left(10^{6}\right.$ $\mathrm{TCID}_{50} / \mathrm{mL}$ ) were mixed with Freund's complete adjuvants and intramuscularly injected into the guinea pigs. After 2 weeks, the second injection was conducted with the field viruses $\left(10^{6} \mathrm{TCID}_{50} / \mathrm{mL}\right)$ mixed with Freund's incomplete adjuvants. The commercial vaccine was injected following the same immunization schedule as the field viruses. After 2 weeks of the second injection, all guinea pigs were euthanized, and the sera were collected. The sera were aliquoted and stored at $-20^{\circ} \mathrm{C}$ until use. All guinea pigs were euthanized by an intramuscular injection of ketamine/xylazine under the guideline for use of controlled drugs.

\section{Nucleotide (NT)/amino acid (AA) sequence and phylogenetic analysis}

Viral genomic DNAs were extracted from tissue homogenates and sera using the DNeasy Blood \&Tissue Kit (Qiagen, Hilden, Germany) according to the manufacturer's instructions. The full-length of the ORF2 gene was amplified using the HotStarTaq Plus Master Mix Kit and ORF2-specific forward primers (5'-GGAATG GTACTCCTCAACTG-3') and reverse primers (5'CTCGTCTTCGGAAGGATTAT-3'). The resulting polymerase chain reaction (PCR) products (1061 bp) were purified by the QIAquick PCR Purification Kit (Qiagen) and were confirmed by DNA nucleotide sequencing (Macrogen, Seoul, South Korea).

To analyze the genetic relatedness between the PCV2 isolates detected from swine farms in Korea, we performed multiple sequence alignment with CLC Main Workbench (Qiagen, Version 7.0.3). A neighbor-joining tree was constructed using MEGA software (Version 7.0), and the reliability of the constructed tree was evaluated by bootstrap analysis of 1000 replications.

\section{Immunofluorescence assay}

PK15 cells were infected with the same titer of PCV2a, $2 \mathrm{~b}, 2 \mathrm{~d}-1$ and $2 \mathrm{~d}-2$ as $200 \mathrm{TCID}_{50}$. For evaluating the binding reactivity of PCV2 and mAbs, infected PK15 cells were fixed with $80 \%$ acetone for $10 \mathrm{~min}$ at $-20^{\circ} \mathrm{C}$. After washing with $1 \times \mathrm{PBS}, \mathrm{mAbs}(1: 200)$ as primary antibodies were reacted by incubating for $1 \mathrm{~h}$ at room temperature (RT). After rinsing, Alexa fluor ${ }^{\text {тм }} 488$ goat anti-mouse immunoglobulin G (IgG, 1:200, Invitrogen, CA, USA) as a secondary antibody was incubated for 30 $\mathrm{min}$ at RT. The nuclei were stained for $5 \mathrm{~min}$ with Hoechst33258 (Invitrogen) diluted in $1 \times$ PBS (1:10,000). For the detection of PCV2-infected cells, fluorescent intensity of PCV2-positive cells per $1 \times 10^{4}$ cellular nuclei 
was measured by ArrayScan VTI HCS (Thermo Scientific, MA, USA), and the number of PCV2-positive cells was counted with by the naked eye.

\section{Viral neutralization assay}

Viral neutralization assay was conducted following the method of Meerts and colleagues [26]. Briefly, 200 $\mathrm{TCID}_{50}$ PCV2 at a volume of $100 \mu \mathrm{L}$ was incubated for $1 \mathrm{~h}$ at $37^{\circ} \mathrm{C}$ with $100 \mu \mathrm{L}$ of serially diluted mAbs or anti-PCV2 sera. After incubation, this mixture was added to $5 \times 10^{3}$ PK15 cells in four wells of a 96-well plate. After $2 \mathrm{~h}$ at $37^{\circ} \mathrm{C}$, the cell culture media were washed twice in $1 \times \mathrm{PBS}$, and fresh medium was added. Cells were fixed 5 days later. PCV2-infected PK15 cells were stained aspreviously described. The neutralization activity of mAbs and serum was expressed as a percentage of the viral neutralization $(\% \mathrm{VN})$ using the number of PCV2-positive cells.

$$
\% V N=100-\left(\frac{\text { the number of PCV2 positive cells with serum }(\mathrm{mAb})}{\text { the number of PCV2 positive cells without serum }(\mathrm{mAb})} \times 100\right)
$$

\section{Statistical analysis}

The results were expressed as the mean \pm standard error (SE) for triplicate experiments $(n=3)$. The statistical significance was determined using Statistica5.5 (StatSoft, OK, USA) with one-way analysis of variance (ANOVA) and post-hoc comparisons between the control group and each treatment group using Duncan's multiple comparison test. A $p$ value $<0.05$ was considered to be statistically significant.

\section{Abbreviations \\ AA: Amino Acid; mAb: monoclonal antibody; NT: Nucleotide; ORF: Open Reading Frame; PCV: Porcine circovirus; PCVAD: Porcine circovirus-associated disease; PDNS: Porcine dermatitis and nephropathy syndrome; PMWS: Postweaning multi-systemic wasting syndrome; PPV: Porcine parvovirus; PRRS: Porcine reproductive respiratory syndrome; SN: Serum neutralization; TCID: Tissue culture infective dose; VN: Viral neutralization}

\section{Acknowledgments}

Not applicable.

\section{Authors' contributions}

SJK conducted most of experiments in this study and produced data. HJK isolated PCV2 and analyzed genetic variation. SHY, HJL, NHL and BHH provided field samples and worked for analysis of the data. SHC designed and supervised the study and analyzed data. SJK and SHC wrote the manuscript. All authors contributed to the final editing and approval of the manuscript.

\section{Funding}

This study was conducted with the funding support from Animal and Plant Quarantine Agency (Project No. QIA M-1543083-2019-21-02), Ministry of Agriculture, Food and Rural Affairs, Republic of Korea. The funder had no role in study design, data collection and analysis, decision to publish, or preparation of manuscript.

\section{Availability of data and materials}

All data generated or analyzed during this study are included in this published article. The phylogenetic data are available in the TreeBase at http://purl.org/
phylo/treebase/phylows/study/TB2:S26750? x-access-code=32ca0fc83c3df17e3 841 fb5c80fae063\&format=html. The study ID on TreeBase is $\mathbf{2 6 7 5 0 .}$

\section{Ethics approval and consent to participate}

The samples were collected from animal by authorized veterinarians during clinical examination following standard procedures and with the agreement of the farmers. Animal owners verbally provided consent for the sample collection. This consent was approved by Institutional Animal Care and Use Committed (IACUC) of Animal and Plant Quarantine Agency (QIA). Animal experiments using guinea pigs were approved by IACUC (Approval number: 2019-465) of QIA and performed according to the Code of Laboratory Animal Welfare Ethics, QIA, Republic of Korea.

Consent for publication

Not applicable.

\section{Competing interests}

The authors declare that they have no competing interests.

\section{Author details}

${ }^{1}$ Viral Disease Division, Animal and Plant Quarantine Agency, 177, Hyeoksin 8-ro, Gimcheon-si, Gyeongsangbuk-do 39660, Republic of Korea. ${ }^{2}$ KBNP, 415, Heungan-daero, Dongan-Gu, Anyang-si, Gyeonggi-do 14059, Republic of Korea.

Received: 3 November 2019 Accepted: 31 August 2020

Published online: 14 September 2020

\section{References}

1. Trible BR, Kerrigan M, Crossland N, Potter M, Faaberg K, Hesse R, Rowland RR. Antibody recognition of porcine circovirus type 2 capsid protein epitopes after vaccination, infection, and disease. Clin Vaccine Immunol. 2011;18(5):749-57. https://doi.org/10.1128/CVI.00418-10.

2. Dupont K, Nielsen EO, Baekbo P, Larsen LE. Genomic analysis of PCV2 isolates from Danish archives and a current PMWS case-control study supports a shift in genotypes with time. Vet Microbiol. 2008;128(1-2):56-64. https://doi.org/10.1016/j.vetmic.2007.09.016.

3. Harmon KM, Gauger PC, Zhang J, Pineyro PE, Dunn DD, Chriswell AJ. Whole-genome sequences of novel porcine Circovirus type 2 viruses detected in swine from Mexico and the United States. Genome Announc. 2015;3(6). https://doi.org/10.1128/genomeA.01315-15.

4. Guo LJ, Lu YH, Wei YW, Huang LP, Liu CM. Porcine circovirus type 2 (PCV2): genetic variation and newly emerging genotypes in China. Virol J. 2010;7: 273. https://doi.org/10.1186/1743-422X-7-273.

5. Segales J, Olvera A, Grau-Roma L, Charreyre C, Nauwynck H, Larsen L, Dupont K, McCullough K, Ellis J, Krakowka S, Mankertz A, Fredholm M, Fossum C, Timmusk S, Stockhofe-Zurwieden N, Beattie V, Armstrong D, Grassland B, Baekbo P, Allan G. PCV-2 genotype definition and nomenclature. Vet Rec. 2008;162(26):867-8. https://doi.org/10.1136/vr.162.26. 867.

6. Timmusk S, Wallgren P, Brunborg IM, Wikstrom FH, Allan G, Meehan B, McMenamy M, McNeilly F, Fuxler L, Belak K, Podersoo D, Saar T, Berg M, Fossum C. Phylogenetic analysis of porcine circovirus type 2 (PCV2) preand post-epizootic postweaning multisystemic wasting syndrome (PMWS) Virus Genes. 2008;36(3):509-20. https://doi.org/10.1007/s11262-008-0217-1.

7. Wiederkehr DD, Sydler T, Buergi E, Haessig M, Zimmermann D, Pospischil A, Brugnera $E$, Sidler X. A new emerging genotype subgroup within PCV-2b dominates the PMWS epizooty in Switzerland. Vet Microbiol. 2009;136(1-2): 27-35. https://doi.org/10.1016/j.vetmic.2008.10.028.

8. Cortey M, Olvera A, Grau-Roma L, Segales J. Further comments on porcine circovirus type 2 (PCV2) genotype definition and nomenclature. Vet Microbiol. 2011;149(3-4):522-3. https://doi.org/10.1016/j.vetmic.2010.11.009.

9. Xiao CT, Halbur PG, Opriessnig T. Global molecular genetic analysis of porcine circovirus type 2 (PCV2) sequences confirms the presence of four main PCV2 genotypes and reveals a rapid increase of PCV2d. J Gen Virol. 2015;96(Pt 7):1830-41. https://doi.org/10.1099/vir.0.000100.

10. Seo HW, Park C, Kang I, Choi K, Jeong J, Park SJ, Chae C. Genetic and antigenic characterization of a newly emerging porcine circovirus type $2 \mathrm{~b}$ mutant first isolated in cases of vaccine failure in Korea. Arch Virol. 2014; 159(11):3107-11. https://doi.org/10.1007/s00705-014-2164-6. 
11. Kwon T, Lee DU, Yoo SJ, Je SH, Shin JY, Lyoo YS. Genotypic diversity of porcine circovirus type 2 (PCV2) and genotype shift to PCV2d in Korean pig population. Virus Res. 2017;228:24-9. https://doi.org/10.1016/j.virusres.2016.11.015.

12. Opriessnig T, Gerber PF, Xiao CT, Halbur PG, Matzinger SR, Meng XJ. Commercial PCV2a-based vaccines are effective in protecting naturally PCV2b-infected finisher pigs against experimental challenge with a 2012 mutant PCV2. Vaccine. 2014;32(34):4342-8. https://doi.org/10.1016/j.vaccine. 2014.06.004.

13. Kekarainen T, Gonzalez A, Llorens A, Segales J. Genetic variability of porcine circovirus 2 in vaccinating and non-vaccinating commercial farms. J Gen Virol. 2014;95(Pt 8):1734-42. https://doi.org/10.1099/vir.0.065318-0.

14. Reiner $\mathrm{G}$, Hofmeister R, Willems $\mathrm{H}$. Genetic variability of porcine circovirus 2 (PCV2) field isolates from vaccinated and non-vaccinated pig herds in Germany. Vet Microbiol. 2015;180(1-2):41-8. https:/doi.org/10.1016/j.vetmic.2015.07.026.

15. Franzo G, Cortey M, Segales J, Hughes J, Drigo M. Phylodynamic analysis of porcine circovirus type 2 reveals global waves of emerging genotypes and the circulation of recombinant forms. Mol Phylogenet Evol. 2016;100:26980. https://doi.org/10.1016/j.ympev.2016.04.028.

16. Xiao CT, Harmon KM, Halbur PG, Opriessnig T. PCV2d-2 is the predominant type of PCV2 DNA in pig samples collected in the U.S. during 2014-2016. Vet Microbiol. 2016;197:72-7. https://doi.org/10.1016/j.vetmic.2016.11.009.

17. Park KH, Oh T, Yang S, Cho H, Kang I, Chae C. Evaluation of a porcine circovirus type 2a (PCV2a) vaccine efficacy against experimental PCV2a, PCV2b, and PCV2d challenge. Vet Microbiol. 2019;231:87-92. https:/doi.org/ 10.1016/j.vetmic.2019.03.002.

18. Lefebvre DJ, Costers S, Van Doorsselaere J, Misinzo G, Delputte PL, Nauwynck HJ. Antigenic differences among porcine circovirus type 2 strains, as demonstrated by the use of monoclonal antibodies. J Gen Virol. 2008; 89(Pt 1):177-87. https://doi.org/10.1099/vir.0.83280-0.

19. Huang LP, Lu YH, Wei YW, Guo L, Liu CM. Identification of one critical amino acid that determines a conformational neutralizing epitope in the capsid protein of porcine circovirus type 2. BMC Microbiol. 2011;11:188. https://doi.org/10.1186/1471-2180-11-188.

20. Jeong J, Park C, Choi K, Chae C. Comparison of three commercial one-dose porcine circovirus type 2 (PCV2) vaccines in a herd with concurrent circulation of PCV2b and mutant PCV2b. Vet Microbiol. 2015;177(1-2):43-52. https://doi.org/10.1016/j.vetmic.2015.02.027.

21. Opriessnig T, O'Neill K, Gerber PF, de Castro AM, Gimenez-Lirola LG, Beach NM, Zhou L, Meng XJ, Wang C, Halbur PG. A PCV2 vaccine based on genotype $2 b$ is more effective than a 2a-based vaccine to protect against PCV2b or combined PCV2a/2b viremia in pigs with concurrent PCV2, PRRSV and PPV infection. Vaccine. 2013;31(3):487-94. https://doi.org/10.1016/j. vaccine.2012.11.030

22. Opriessnig T, Xiao CT, Halbur PG, Gerber PF, Matzinger SR, Meng XJ. A commercial porcine circovirus (PCV) type 2a-based vaccine reduces PCV2d viremia and shedding and prevents PCV2d transmission to naive pigs under experimental conditions. Vaccine. 2017;35(2):248-54. https://doi.org/10.1016/ j.vaccine.2016.11.085.

23. Rose N, Andraud M, Bigault L, Jestin A, Grasland B. A commercial PCV2abased vaccine significantly reduces $P C V 2 b$ transmission in experimental conditions. Vaccine. 2016;34(33):3738-45. https://doi.org/10.1016/j.vaccine. 2016.06.005.

24. Beach NM, Ramamoorthy S, Opriessnig T, Wu SQ, Meng XJ. Novel chimeric porcine circovirus (PCV) with the capsid gene of the emerging PCV2b subtype cloned in the genomic backbone of the non-pathogenic PCV1 is attenuated in vivo and induces protective and cross-protective immunity against PCV2b and PCV2a subtypes in pigs. Vaccine. 2010;29(2):221-32. https://doi.org/10.1016/j.vaccine.2010.10.050.

25. Chung CJ, Cha SH, Grimm AL, Ajithdoss D, Rzepka J, Chung G, Yu J, Davis WC, Ho CS. Pigs that recover from porcine reproduction and respiratory syndrome virus infection develop cytotoxic CD4+CD8+ and CD4+CD8- Tcells that kill virus infected cells. PLoS One. 2018;13(9):e0203482. https://doi. org/10.1371/journal.pone.0203482.

26. Meerts P, Van Gucht S, Cox E, Vandebosch A, Nauwynck HJ. Correlation between type of adaptive immune response against porcine circovirus type 2 and level of virus replication. Viral Immunol. 2005;18(2):333-41. https://doi. org/10.1089/vim.2005.18.333.

\section{Publisher's Note}

Springer Nature remains neutral with regard to jurisdictional claims in published maps and institutional affiliations.

Ready to submit your research? Choose BMC and benefit from:

- fast, convenient online submission

- thorough peer review by experienced researchers in your field

- rapid publication on acceptance

- support for research data, including large and complex data types

- gold Open Access which fosters wider collaboration and increased citations

- maximum visibility for your research: over $100 \mathrm{M}$ website views per year

At BMC, research is always in progress.

Learn more biomedcentral.com/submissions 